\section{ECONOMICS}

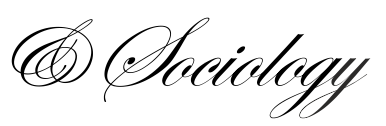

Castro-González, S., Rey-Ares, L., Fernández-López, S., \& Daoudi, D. (2020).

The effect of self-control upon participation in voluntary pension schemes.

Economics and Sociology, 13(1), 11-23. doi:10.14254/2071-789X.2020/13-1/1

\title{
THE EFFECT OF SELF-CONTROL UPON PARTICIPATION IN VOLUNTARY PENSION SCHEMES
}

\author{
Sandra Castro-González, \\ Department of Business \\ Organization and \\ Commercialization, \\ Universidade de Santiago de \\ Compostela, Lugo, Spain \\ E-mail:sandra.castro@,usc.es \\ ORCID 0000-0002-8206-1776
}

Lucía Rey-Ares,

Business Department, Universidade

da Coruña, Ferrol, Spain

E-mail:Lucia.rey.ares@udc.es

ORCID 0000-0002-5165-742X

\section{Sara Fernández-López,}

Department of Financial

Economics and Accounting,

Universidade de Santiago de

Compostela, Santiago de

Compostela, Spain

E-mail:

sara.fernandez.lopez@usc.es

ORCID 0000-0003-2496-4333

Djamila Daoudi,

Department of Financial

Economics and Accounting,

Universidade de Santiago de

Compostela, Santiago de

Compostela, Spain

E-mail:djamila.daoudi@,rai.usc.es

ORCID 0000-0003-2815-1866

Received: June, 2019

1st Revision: November, 2019

Accepted: February, 2020

DOI: $10.14254 / 2071$ -

789X.2020/13-1/1

JEL Classification: G40, G41
ABSTRACT. Population ageing, together with the recent economic downturn and its aftermath, are giving considerable cause for concern as regards the future sustainability of public pension systems. Voluntary pension schemes emerge here as an alternative to supplement the public pension pillar, and therefore, understanding how individuals make their financial decisions when participating in voluntary pension schemes becomes a question of key importance. There is a growing literature aimed at analysing this issue, but few studies to date have analysed the effect of behavioural traits on participation in voluntary pension schemes. Particularly, an analysis of the effect of self-control on this financial decision will be the aim of this paper. Based on data from the International Survey of Adult Financial Literacy, this paper analyses, through probit regression models, the effect of financial self-control, besides other control variables, e.g., gender, on the holding of financial assets for retirement savings. Empirical evidence reveals that higher levels of financial self-control are positively associated with saving for retirement. Moreover, when this variable is considered, the statistically significant effect of other driving forces traditionally highlighted by previous literature disappears. Therefore, our empirical evidence supports the need to consider behavioural issues in explaining individuals' financial decisions.
Keywords: self-control, driving forces, saving for retirement, OECD/INFE toolkit, Spain 


\section{Introduction}

The sustainability of the public pension pillar is based on the behaviour of three main factors, namely: the demography, the labour market and the rules governing the distribution of the pension. In this regard, population ageing, together with the recent economic downturn and its aftermath, is giving considerable cause for concern as regards the future sustainability of the public pension pillar. Therefore, understanding how individuals make their financial decisions when participating in voluntary pension schemes, and ultimately, understanding whether this alternative might constitute a real option to supplement retirement savings obtained from the public pension pillar, are questions of key importance for economists and policy makers.

Previous literature acknowledges the influence of psychological and attitudinal traits in the management of personal finances (Achtziger, Huber, Kenning, Raab, \& Reisch, 2015; Farrell, Fry \& Risse, 2016). Hershey (2004) states that although demographic traits do influence retirement saving decisions, their effect is mediated through the psyche, thus recognizing the importance of psychological traits. Among these traits, self-control, understood as the restraint exercised over one's own impulses, desires or emotions, has emerged as one of the driving forces of financial decisions (Gathergood, 2012). There is evidence indicating that lack of selfcontrol is responsible for many individual and societal problems, such as impulse-control problems, procrastination and overspending (Achtziger et al., 2015; Baumeister, Vohs \& Tice, 1994).

But in spite of this evidence, few studies to date have analysed the influence of selfcontrol on the decision to invest in retirement assets (Strömbäck, Lind, Skagerlund, Västfjäll, \& Tinghög, 2017). To the best of our knowledge, only three papers have explicitly addressed this relationship (Ameriks, Caplin, Leahy, \& Tyler, 2007; Hira, Rock, \& Loibl, 2009; Kimball \& Shumway, 2009), without finding strong empirical evidence supporting it. In this regard, these papers present two major limitations. Firstly, they use one or two-item scales to measure a complex concept such as self-control; and secondly, they do not consider financial literacy as a driving force of retirement assets.

This paper aims to fill these gaps in the literature. Under the theoretical lens of the behavioural life-cycle hypothesis, it explores how individuals' self-control, together with other control variables, influences their decision to invest in retirement assets. Using a sample of 8,554 Spanish individuals in 2015, we first construct and validate a multi-item scale of financial self-control by applying Exploratory Factorial Analysis (EFA) and other methodological verifications. Second, we test whether the effect of individuals' self-control affects their decision to hold retirement assets. And, finally, the robustness of this relationship is tested by controlling for the individuals' level of financial literacy.

This paper contributes to the literature in several ways. Firstly, it expands the recent literature investigating the effect of self-control on saving for retirement, which is still rather limited (Strömbäck et al., 2017). Secondly, we construct a multi-item scale measure of selfcontrol based on a higher number of specific financial questions than previous research. In so doing, we add to the literature that claims to design a reliable self-control measure for financial studies (Lown, 2011). Thirdly, by controlling for financial literacy, we reduce the omitted variable bias problem. Fourthly, unlike previous studies, we use a larger and more diverse sample, which leads to more robust results (Farrell et al., 2016). Finally, we find empirical evidence of the effect of self-control on holding retirement assets. With these results in mind, several recommendations to improve households' financial behaviour are proposed.

The remainder of the paper is structured as follows. After this introductory section, Section 1 presents the literature review. Section 2 describes the methodology and the 
econometric approach. Section 3 discusses the empirical outcome, and finally, Section 4 summarizes the concluding remarks.

\section{Literature review}

Self-control can be defined as the individual's ability to control his/her own impulses, emotions and desires, especially in difficult circumstances. This concept is also characterized, as Gathergood (2012) states, as a time-inconsistency problem. In this regard, an inadequate selfcontrol might lead individuals to follow first or dominant impulses or to not be able to resist temptations.

The proposal of self-control as a potential driving force of households' saving and consumption decisions was suggested by Shefrin and Thaler (1988), when they formulated the behavioural life-cycle (BLC) hypothesis. This hypothesis constitutes an extension of the traditional life-cycle model of Modigliani and Brumberg (1954), aimed at overcoming some of its limitations. Namely, Shefrin and Thaler (1988) indicated that individuals were not as rational as the Modigliani and Brumberg (1954) model predicted, stating that individuals face two conflicting viewpoints; i.e., one that focuses on the long-term and the other, myopic, that focuses on the short-term or current situation. And here self-control emerges as a driving force aimed at controlling the individuals' own impulses regarding their consumption behaviour, in order to accumulate savings. Thus, the ability to control impulses and emotions can influence the individuals' decision-making (Atkinson \& Messy, 2011), relating to individuals' ability to successfully manage their personal finances (Farrell et al., 2016)

In this regard, empirical evidence confirms that a lack of self-control is related to poor financial behaviours, such as a lack of saving (Kimball \& Shumway, 2009; Lown, Kim, \& Gutter, 2015), over-indebtedness (Gathergood, 2012), unhealthy credit card-use (Sotiropoulos \& d'Astous, 2013; Wang, Lu, \& Malhotra, 2011), or lack of financial help-seeking (Lim, Heckman, Montalto, \& Letkiewicz, 2014), among others. Although the relationship between self-control and financial behaviours has rapidly grown in importance over the last ten years, several financial behaviours such as saving for retirement have been underexplored in the empirical literature (Strömbäck et al., 2017). To the best of our knowledge, Ameriks et al. (2007), Kimball and Shumway (2009) and Hira et al. (2009) are the only papers that explicitly address this relationship.

More specifically, using a sample of 320 Americans, Kimball and Shumway (2009) found that the lack of self-control, measured through two items mainly focused on purchasing behaviour, negatively influences not only the individual's overall savings but also the retirement savings. In contrast, Ameriks et al. (2007) found, for a sample of 362 American households, that self-control problems do not influence the amount of savings in retirement assets. These last authors construct a measure of self-control problems by proposing several questions concerning a hypothetical choice scenario.

Hira et al. (2009) also studied a sample of 911 high-income American households in 2005. The authors used a five-point scale variable representing individuals who like to plan for the future as a proxy of perceived self-control. Similarly to Ameriks et al. (2007), the empirical results failed to confirm self-control as a significant driving force of the decision to hold retirement assets.

According to Ameriks et al. (2007), the lack of a statistically significant effect of selfcontrol on retirement savings in two out of the three above-mentioned studies can be partially explained by the fact that retirement savings tend to be illiquid assets. In this respect, it might be harder to avoid the temptation to consume liquid assets (e.g., money in current accounts), whereas illiquid ones (e.g., voluntary pension plans, life insurances...) tend to be less affected 
by self-control problems. However, in this paper we add two additional potential explanations for this lack of significance. Firstly, the measures of self-control used by Ameriks et al. (2007) and Hira et al. (2009) are mostly based on questions related to choice or planning behaviour, rather than focused on financial behaviours. Moreover, the three above-mentioned papers use one or two-item scales to measure self-control, which could by a rather limited approach to capture financial self-control. Secondly, none of the three studies have considered financial literacy as a correlate, in spite of numerous studies that have proved that the individual's financial literacy affects the decision to save for retirement (Lusardi \& Mitchell, 2011; Ricci \& Caratelli, 2017).

To sum up, the few studies on the topic have found scarce empirical evidence confirming the relationship between self-control and investment in retirement assets. In this paper, we construct a robust measure of self-control from questions specifically aimed at collecting information on financial behaviours (i.e., a financial self-control measure) and control by the individuals' level of financial literacy when estimating the effect of correlates on the decision to save for retirement. From this empirical approach and drawing on the arguments stemming from the BLC hypothesis, we propose that the individual's self-control does influence the probability of holding retirement assets; this constitutes our working hypothesis.

\section{Methodology}

Data comes from the International Survey of Adult Financial Literacy, a questionnairebased survey developed by the OECD International Network on Financial Education (INFE). This survey is aimed at collecting information on financial literacy and financial inclusion in different OECD countries. Specifically, this paper focuses on a sample comprised of 8,554 Spanish individuals interviewed in 2015.

\subsection{Self-control measurement: Exploratory Factorial Analysis (EFA)}

The review of previous literature reveals a lack of consensus regarding the conceptualization of self-control. As Achtziger et al. (2015) point out, self-control is measured in some cases as a general psychological resource capable of controlling the thoughts or impulses of individuals; but in other cases, it is measured through more specific issues, such as money spending behaviour or self-reported measures of self-control.

The lack of a homogeneous conceptualization of self-control is also reflected in the lack of agreement when it comes to its measurement. Thus, most of the previous literature on financial behaviour uses a single-item scale to measure self-control; but there is also no agreement when it comes to operationalizing this item. Thus, Hira et al. (2009) operationalize self-control through an item related to planning for the future, whereas Gathergood (2012) and Gathergood and Weber (2014) consider an item related to the purchasing power and the purchasing decision. A second group of studies, although in the minority, considers self-control as a multi-item variable. However, once more, there is not full accord with the multi-item scale. Finally, a third group of studies, e.g., Strömbäck et al. (2017), uses a combination of more personal or psychological items proposed by Tangney, Baumeister, \& Boone (2004) and financial items are related to the proposal of Antonides, De Groot and Van Raaij (2011). To the best of our knowledge, Antonides et al. (2011) are among the first authors to attempt to develop a self-control scale in the field of finance. Their items are closely related to the short-term orientation of individuals.

After reviewing the available literature on financial behaviour and self-control, two main shortcomings have been identified regarding the constructed scales of self-control. Firstly, 
these scales are either based on questions concerning personal, psychological and/or motivational issues (i.e., 'general self-control'), or on questions on financial issues (i.e., 'financial self-control'). Secondly, the latter scales, i.e., the ones based on financial issues, are constructed based exclusively on a specific financial behaviour, such as the use of credit cards or money spending. Both shortfalls limit the ability of self-control scales to capture the complexity of the concept. In order to overcome them, we have created and validated a new self-control scale, assuming that it should be a multi-item scale with general financial questions. In so doing, we used Exploratory Factorial Analysis (EFA) and other methodological verifications as shown next.

The methodological process to identify the latent dimensionality of self-control and develop the scale was EFA. Initially, to determine the factors we introduced twelve attitudinal and behavioural statements where people have to select a position in a five-point Likert scale (from 1 -completely agree- to 5 -completely disagree-). Four factors were extracted, but two of them were automatically discarded because their factor loadings were too low. After analysing the content of the two remaining factors, only one of them, related to financial selfcontrol, stood out.

In a second step, a second factorial analysis was carried out with the items of the selected factor. Kaiser-Meyer-Olkin (KMO) returned a result of 0.643 and Bartlett's Test of Sphericity was significant $(\mathrm{p}<0.000)$; i.e., both values were considered appropriate (Hair, Black, Babin, Anderson, \& Tatham, 2006), which confirmed the suitability of our data for factor analysis.

EFA used principal component analysis as extraction methodology to simplify the factor structure and Varimax as rotation method. The communalities were above 0.528 , which suggests that the items adequately explain the variance of the original items. The factors explain $58.43 \%$ of scale total variance. It is composed of three items with loadings ranging from the lowest of 0.727 to the highest of 0.801 .

Cronbach's alpha is 0.642 , which shows a good internal consistency of the scale. Table 1 summarizes all EFA information.

Table 1. Factor analysis and reliability of self-control scale

\begin{tabular}{|c|c|c|c|}
\hline & $\begin{array}{l}\text { Cross factor } \\
\text { loadings }\end{array}$ & $\begin{array}{l}\text { Item to total } \\
\text { correlation }\end{array}$ & $\begin{array}{c}\text { Cronbach's } \\
\text { alpha }\end{array}$ \\
\hline \multicolumn{4}{|l|}{ Self-control $K M O=0.643 ;$ Eigenvalue: 1.753} \\
\hline $\begin{array}{l}\text { I tend to live for today and let tomorrow take care of } \\
\text { itself }\end{array}$ & 0.764 & 0.583 & \multirow{3}{*}{0.642} \\
\hline $\begin{array}{l}\text { I find it more satisfying to spend money than to save } \\
\text { it for the long term }\end{array}$ & 0.801 & 0.641 & \\
\hline Money is there to be spent & 0.727 & 0.528 & \\
\hline
\end{tabular}

Source: own compilation from INFE

Scale reliability was confirmed, so we proceeded to create a new variable where all items converge. Low or negative values for the created variable represent low levels of selfcontrol, whereas high or positive values correspond to high levels of self-control.

\subsection{Definition and measurement of the variables}

The dependent variable of the analysis is the decision to hold retirement assets (RET_ASSET). It is measured as a dummy variable taking the value 1 if the individual, either 
personally or jointly, held any pension or retirement product - excluding compulsory products - at the time of the interview; and value 0 otherwise.

The main independent variable deals with the individual's level of self-control. In this respect, two measures are used. First, the SELFC variable is the continuous variable constructed by applying the EFA, as described in the previous section. Second, similarly to Strömbäck et al. (2017), a dummy variable (SEFC_D) is also created. The SELF_C variable takes the value 1 for those individuals whose self-control estimated score (SELFC) is above the median level of self-control; and 0 otherwise.

The remaining independent variables are control variables which have been often highlighted by the financial literature as potential drivers of the decision to save for retirement. Most of them are dummy variables that have been re-coded from the original questionnaire. Table 2 contains more detailed information concerning the definition of these independent variables.

Table 2. Variable definitions

\begin{tabular}{|c|c|}
\hline VARIABLES & DEFINITION \\
\hline $\begin{array}{l}\text { Retirement assets } \\
\left(R E T \_A S S E T\right)\end{array}$ & $\begin{array}{l}\text { Dummy variable set to } 1 \text { if the respondent, personally or jointly, holds a pension or } \\
\text { retirement product - excluding compulsory products; and to } 0 \text { otherwise. }\end{array}$ \\
\hline $\begin{array}{l}\text { Self-control } \\
(S E L F C)\end{array}$ & Continuous variable constructed by applying the EFA \\
\hline $\begin{array}{l}\text { Self-control } \\
\left(S E L F C \_D\right)\end{array}$ & $\begin{array}{l}\text { Dummy variable set to } 1 \text { if the self-control estimated score (SELFC) is above the median } \\
\text { level of self-control; and to } 0 \text { otherwise. }\end{array}$ \\
\hline $\begin{array}{l}\text { Gender } \\
(G E N D E R)\end{array}$ & Dummy variable set to 1 if the respondent is female; and to 0 if male \\
\hline $\begin{array}{l}\text { Age }^{1} \\
\left(L N A G E ; L N A G E^{2}\right)\end{array}$ & Natural logarithm of the respondent's age (in years) \\
\hline $\begin{array}{l}\text { Employment } \\
\text { situation } \\
(\text { EMPLOY \#) }\end{array}$ & $\begin{array}{l}\text { Respondent's current employment situation is: } \\
\text { Employed or self-employed (1) [reference category]; } \\
\text { Unemployed (2); } \\
\text { Retired (3); } \\
\text { Other including looking after the home; unable to work due to sickness or ill- } \\
\text { health; not working and not looking for work; student and so on (4) }\end{array}$ \\
\hline $\begin{array}{l}\text { Income bracket } \\
\text { (INCOME \#) }\end{array}$ & $\begin{array}{l}\text { Respondent's household yearly income bracket is: } \\
\text { Below 14,500 euros (1) [reference category]; } \\
\text { Between 14,500 and 45,000 euros (2) } \\
\text { Above 45,000 euros (3) }\end{array}$ \\
\hline $\begin{array}{l}\text { Educational } \\
\text { attainment } \\
(E D U \#)\end{array}$ & $\begin{array}{l}\text { Respondent's formal education consists of six levels: } \\
\text { No formal education (1) [reference category]; } \\
\text { Complete primary education (2); } \\
\text { Some secondary education (3); } \\
\text { Complete secondary education (4); } \\
\text { Technical/vocational education (5); } \\
\text { University education (6) }\end{array}$ \\
\hline $\begin{array}{l}\text { Children under } 18 \\
\left(C H I L D 18 \_D\right)\end{array}$ & $\begin{array}{l}\text { Dummy variable set to } 1 \text { if the respondent (or his/her partner) has children under the age } \\
\text { of } 18 \text { living in the household; and to } 0 \text { otherwise }\end{array}$ \\
\hline $\begin{array}{l}\text { Marital status } \\
(M A R R I E D)\end{array}$ & $\begin{array}{l}\text { Dummy variable equal to } 1 \text { if the respondent is married and living with spouse or has a } \\
\text { registered partnership; and to } 0 \text { otherwise }\end{array}$ \\
\hline $\begin{array}{l}\text { Financial literacy }{ }^{2} \\
\left(A B C \_D\right)\end{array}$ & $\begin{array}{l}\text { Dummy variable set to } 1 \text { if the respondent correctly answers the three internationally } \\
\text { comparable questions on financial literacy proposed by Lusardi (2008) and commonly } \\
\text { known as the "ABC" or "core" of financial literacy; and to } 0 \text { otherwise }\end{array}$ \\
\hline
\end{tabular}

Notes: ${ }^{1}$ The LNAGE ${ }^{2}$ variable was included in order to capture potential non-linearities. ${ }^{2}$ The three questions known as the "core" of financial literacy refer to the concepts of interest compounding, real vs. nominal returns, and portfolio diversification.

Source: own compilation 


\subsection{Estimation strategy}

This paper is aimed at analysing the effect of self-control upon the decision to invest in retirement assets. To accomplish this objective, the multivariate analysis involves a two-stage process. In the first stage, after applying EFA, as previously stated, a scale for measuring individuals' self-control is defined. In the second stage, a probit model is used to model a nonlinear relationship between the dummy dependent variable and a set of independent variables among these latter, the scale created in the first stage is introduced as an explanatory variable.

The probit model specification is established as follows:

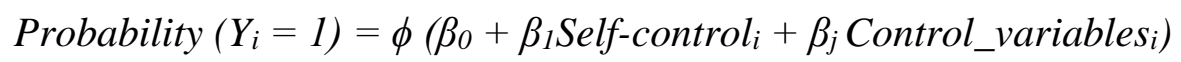

The dependent variable $(\mathrm{Yi})$ quantifies the individual's probability of holding retirement assets, $i$ is the index of the individual, and $\phi$ denotes the standard normal distribution function. Self-control refers to both the scale of an individual's self-control and the dummy variable for self-control. Control_variables refers to the set of control variables defined in Table 2.

\section{Empirical results}

\subsection{Univariate analysis}

Summary statistics of selected dependent and independent variables are displayed in Table 3. The final sample comprises 8,554 individuals with an average age of 47 years, and an almost equal gender distribution. Most of the respondents are married (65.7\%) and about one third of them $(30.7 \%)$ have children under the age of 18 at home. Concerning educational attainment, $22.8 \%$ of respondents have completed secondary education, $15 \%$ primary education, and $22.3 \%$ tertiary education, while the remaining percentage corresponds to individuals who have no formal education (2.4\%) or another type of education. Almost half of the sample is employed or self-employed (53.1\%) and their households' average annual income ranges between $€ 14,500$ and $€ 45,000$ (50.5\%). Only $23.9 \%$ have invested in voluntary retirement assets, while a lower percentage, close to one-fifth of the sample (18.3\%), correctly answered all the questions on financial literacy.

Focusing on self-control, about $52.4 \%$ of the sample are individuals whose level of selfcontrol is above the median level of self-control. Over half are women (53.6\%), married $(69.6 \%)$ and $34.5 \%$ have children under the age of 18 years. On the other hand, of those who can be considered individuals with low self-control over half are men (53.6\%), married $(61.3 \%)$ and the majority (73.4\%) do not have children under the age of 18. Regarding educational attainment, there are no major differences between individuals with high self-control and individuals with low self-control; nor regarding financial literacy.

Furthermore, as concerns employment and economic situation, both subsamples behave similarly. And finally, as regards retirement assets, respondents with high self-control hold a slightly higher percentage $(26.4 \%)$ of these assets than respondents with low self-control $(21.1 \%)$. 
Table 3. Descriptive statistics: global sample and subsamples

\begin{tabular}{|c|c|c|c|c|c|c|c|c|c|c|}
\hline \multirow{2}{*}{ Variable } & & \multicolumn{3}{|c|}{ GLOBAL SAMPLE } & \multicolumn{3}{|c|}{ SUBSAMPLE SELF_D=0 } & \multicolumn{3}{|c|}{ SUBSAMPLE SELF_D=1 } \\
\hline & & Obs. & Mean & Std. Dev. & Obs. & Mean & Std. Dev. & Obs. & Mean & Std. Dev. \\
\hline RET_ASSI & & 7,678 & 0.239 & 0.427 & 3,588 & 0.211 & 0.408 & 4,090 & 0.264 & 0.441 \\
\hline GENDER & & 8,554 & 0.502 & 0.500 & 4,073 & 0.464 & 0.499 & 4,481 & 0.536 & 0.499 \\
\hline $\mathrm{AGE}^{*}$ & & 8,554 & 47.22 & 15.77 & 4,073 & 47.50 & 16.38 & 4,481 & 46.97 & 15.19 \\
\hline \multirow{4}{*}{ EMPLOY } & 1 & 8,553 & 0.531 & 0.499 & 4,072 & 0.499 & 0.500 & 4,481 & 0.561 & 0.496 \\
\hline & 2 & 8,553 & 0.138 & 0.345 & 4,072 & 0.145 & 0.352 & 4,481 & 0.133 & 0.339 \\
\hline & 3 & 8,553 & 0.161 & 0.367 & 4,072 & 0.188 & 0.391 & 4,481 & 0.136 & 0.343 \\
\hline & 4 & 8,553 & 0.169 & 0.375 & 4,072 & 0.168 & 0.374 & 4,481 & 0.171 & 0.376 \\
\hline \multirow{3}{*}{ INCOME } & 1 & 7,720 & 0.361 & 0.480 & 3,680 & 0.376 & 0.484 & 4,040 & 0.347 & 0.476 \\
\hline & 2 & 7,720 & 0.505 & 0.500 & 3,680 & 0.506 & 0.500 & 4,040 & 0.504 & 0.500 \\
\hline & 3 & 7,720 & 0.134 & 0.341 & 3,680 & 0.118 & 0.323 & 4,040 & 0.149 & 0.356 \\
\hline \multirow{6}{*}{ EDU } & 1 & 8,552 & 0.024 & 0.152 & 4,072 & 0.028 & 0.165 & 4,480 & 0.020 & 0.140 \\
\hline & 2 & 8,552 & 0.150 & 0.357 & 4,072 & 0.163 & 0.369 & 4,480 & 0.138 & 0.345 \\
\hline & 3 & 8,552 & 0.272 & 0.445 & 4,072 & 0.286 & 0.452 & 4,480 & 0.259 & 0.438 \\
\hline & 4 & 8,552 & 0.228 & 0.419 & 4,072 & 0.236 & 0.424 & 4,480 & 0.221 & 0.415 \\
\hline & 5 & 8,552 & 0.104 & 0.305 & 4,072 & 0.097 & 0.296 & 4,480 & 0.109 & 0.312 \\
\hline & 6 & 8,552 & 0.223 & 0.417 & 4,072 & 0.190 & 0.393 & 4,480 & 0.254 & 0.435 \\
\hline \multicolumn{2}{|c|}{ CHILD18_d } & 8,551 & 0.307 & 0.461 & 4,071 & 0.266 & 0.442 & 4,480 & 0.345 & 0.475 \\
\hline \multicolumn{2}{|c|}{ MARRIED } & 8,551 & 0.657 & 0.475 & 4,071 & 0.613 & 0.487 & 4,480 & 0.696 & 0.460 \\
\hline \multicolumn{2}{|l|}{ SELF } & 8,491 & 0.000 & 1.000 & 4,073 & -0.840 & 0.683 & 4,418 & 0.775 & 0.491 \\
\hline \multicolumn{2}{|l|}{ SELF_D } & 8,554 & 0.524 & 0.499 & & & & & & \\
\hline \multicolumn{2}{|l|}{ ABC_D } & 8,554 & 0.183 & 0.387 & 4,073 & 0.173 & 0.378 & 4,481 & 0.192 & 0.394 \\
\hline
\end{tabular}

Notes: AGE variable is not in logs. In the case of the dummy and factor variables, the value of the mean reports the percentage of people who fulfil the condition according to which those variables take the value equal to 1. Obs. and Std. Dev. stand for observations and standard deviation, respectively.

Source: own compilation from INFE

\subsection{Multivariate analysis}

To test the effect of self-control on the decision to invest in retirement assets, different empirical models are estimated. Model 1 constitutes the base model including all the control variables. Models 2 and 3 include the continuous and dummy variables measuring the individuals' self-control, respectively. Models 4 and 5 add the dummy variable referred to financial literacy, and Model 6 incorporates the interaction term between self-control and financial literacy. Table 4 displays the estimated marginal effects of the six econometric models.

Most of the results obtained confirm the proposed hypothesis; i.e., a high level of selfcontrol is positively associated with holding a pension or retirement asset. Particularly, the estimates indicate that an individual with a level of self-control over the median has around $2.8 \%$ higher probability of investing in retirement assets, compared with an individual with a low self-control. These results are consistent with the findings of Kimbal and Shumway (2009).

Unlike previous studies on the relationship between self-control and retirement savings, our analyses incorporate a variable capturing the individual's level of financial literacy. In this respect, a non-negligible number of empirical studies have found strong evidence of the effect of financial literacy on this financial behaviour (e.g., Ricci \& Caratelli, 2017), as also confirmed by our empirical evidence. Moreover, even controlling for the individuals' financial literacy (Lusardi, 2008), the self-control variable remains statistically significant and positively related to holding retirement assets. 
Table 4. Holding retirement assets: probit estimates

\begin{tabular}{|c|c|c|c|c|c|c|c|}
\hline & & M1 & M2 & M3 & M4 & M5 & M6 \\
\hline \multirow{2}{*}{\multicolumn{2}{|c|}{ GENDER }} & $-0.026 * *$ & $-0.028 * *$ & $-0.027 * *$ & $-0.024 *$ & $-0.023^{*}$ & $-0.023^{*}$ \\
\hline & & $(0.010)$ & $(0.010)$ & $(0.010)$ & $(0.010)$ & $(0.010)$ & $(0.010)$ \\
\hline \multirow{2}{*}{\multicolumn{2}{|c|}{ LNAGE }} & $4.324 * * *$ & $4.259 * * *$ & $4.355 * * *$ & $4.240 * * *$ & $4.332 * * *$ & $4.331 * * *$ \\
\hline & & $(0.649)$ & $(0.647)$ & $(0.646)$ & $(0.645)$ & $(0.644)$ & $(0.644)$ \\
\hline \multirow{2}{*}{\multicolumn{2}{|c|}{$\mathrm{LNAGE}^{2}$}} & $-0.526 * * *$ & $-0.517 * * *$ & $-0.530 * * *$ & $-0.515 * * *$ & $-0.527 * * *$ & $-0.527 * * *$ \\
\hline & & $(0.086)$ & $(0.086)$ & $(0.086)$ & $(0.086)$ & $(0.085)$ & $(0.085)$ \\
\hline \multirow{6}{*}{$\begin{array}{l}\text { EMPLOY } \\
\text { [Ref. 1] }\end{array}$} & \multirow{2}{*}{2} & $-0.083 * * *$ & $-0.083 * * *$ & $-0.082 * * *$ & $-0.082 * * *$ & $-0.081 * * *$ & $-0.081 * * *$ \\
\hline & & $(0.014)$ & $(0.014)$ & $(0.014)$ & $(0.014)$ & $(0.014)$ & $(0.014)$ \\
\hline & \multirow{2}{*}{3} & $-0.139 * * *$ & $-0.139 * * *$ & $-0.137 * * *$ & $-0.138 * * *$ & $-0.136 * * *$ & $-0.136 * * *$ \\
\hline & & $(0.016)$ & $(0.016)$ & $(0.016)$ & $(0.016)$ & $(0.016)$ & $(0.016)$ \\
\hline & \multirow{2}{*}{4} & $-0.091 * * *$ & $-0.094 * * *$ & $-0.091 * * *$ & $-0.094 * * *$ & $-0.091 * * *$ & $-0.091 * * *$ \\
\hline & & $(0.015)$ & $(0.015)$ & $(0.015)$ & $(0.015)$ & $(0.015)$ & $(0.015)$ \\
\hline \multirow{4}{*}{$\begin{array}{l}\text { INCOME } \\
\text { [Ref. 1] }\end{array}$} & \multirow{2}{*}{2} & $0.100 * * *$ & $0.100 * * *$ & $0.101 * * *$ & $0.099 * * *$ & $0.100 * * *$ & $0.100 * * *$ \\
\hline & & $(0.012)$ & $(0.012)$ & $(0.012)$ & $(0.012)$ & $(0.012)$ & $(0.012)$ \\
\hline & \multirow{2}{*}{3} & $0.271 * * *$ & $0.270 * * *$ & $0.272 * * *$ & $0.265 * * *$ & $0.266 * * *$ & $0.266 * * *$ \\
\hline & & $(0.021)$ & $(0.021)$ & $(0.021)$ & $(0.021)$ & $(0.021)$ & $(0.021)$ \\
\hline \multirow{10}{*}{$\begin{array}{l}\text { EDU } \\
\text { [Ref. 1] }\end{array}$} & \multirow{2}{*}{2} & 0.053 & 0.047 & 0.05 & 0.046 & 0.049 & 0.049 \\
\hline & & $(0.057)$ & $(0.058)$ & $(0.057)$ & $(0.058)$ & $(0.057)$ & $(0.057)$ \\
\hline & \multirow{2}{*}{3} & $0.099 \dagger$ & $0.094 \dagger$ & $0.096 \dagger$ & $0.092 \dagger$ & $0.094 \dagger$ & $0.094 \dagger$ \\
\hline & & $(0.055)$ & $(0.055)$ & $(0.055)$ & $(0.056)$ & $(0.055)$ & $(0.055)$ \\
\hline & \multirow{2}{*}{4} & $0.169 * *$ & $0.163 * *$ & $0.166^{* *}$ & $0.157 * *$ & $0.160 * *$ & $0.160 * *$ \\
\hline & & $(0.060)$ & $(0.060)$ & $(0.060)$ & $(0.060)$ & $(0.060)$ & $(0.060)$ \\
\hline & \multirow{2}{*}{5} & $0.142 *$ & $0.136^{*}$ & $0.138^{*}$ & $0.130^{*}$ & $0.132 *$ & $0.133^{*}$ \\
\hline & & $(0.063)$ & $(0.063)$ & $(0.063)$ & $(0.063)$ & $(0.063)$ & $(0.063)$ \\
\hline & \multirow{2}{*}{6} & $0.187 * *$ & $0.180 * *$ & $0.182 * *$ & $0.170 * *$ & $0.172 * *$ & $0.173 * *$ \\
\hline & & $(0.061)$ & $(0.062)$ & $(0.061)$ & $(0.062)$ & $(0.061)$ & $(0.062)$ \\
\hline \multirow{2}{*}{\multicolumn{2}{|c|}{ CHILD18_D }} & 0.007 & 0.006 & 0.005 & 0.006 & 0.005 & 0.005 \\
\hline & & $(0.012)$ & $(0.012)$ & $(0.012)$ & $(0.012)$ & $(0.012)$ & $(0.012)$ \\
\hline \multirow{2}{*}{\multicolumn{2}{|c|}{ MARRIED }} & -0.004 & -0.006 & -0.007 & -0.006 & -0.007 & -0.007 \\
\hline & & $(0.012)$ & $(0.012)$ & $(0.012)$ & $(0.012)$ & $(0.012)$ & $(0.012)$ \\
\hline \multirow{2}{*}{\multicolumn{2}{|c|}{ SELF }} & & $0.012 *$ & & $0.012 *$ & & \\
\hline & & & $(0.005)$ & & $(0.005)$ & & \\
\hline \multirow{2}{*}{\multicolumn{2}{|c|}{ SELF_D }} & & & $0.028 * *$ & & $0.028 * *$ & $0.027^{*}$ \\
\hline & & & & $(0.009)$ & & $(0.009)$ & $(0.011)$ \\
\hline \multirow{2}{*}{\multicolumn{2}{|c|}{ ABC_D }} & & & & $0.030 *$ & $0.031 * *$ & 0.028 \\
\hline & & & & & $(0.012)$ & $(0.012)$ & $(0.018)$ \\
\hline \multirow{2}{*}{\multicolumn{2}{|c|}{ SELFABC_D }} & & & & & & 0.005 \\
\hline & & & & & & & $(0.022)$ \\
\hline \multicolumn{2}{|l|}{$\mathrm{N}$} & 6,946 & 6,911 & 6,946 & 6,911 & 6,946 & 6,946 \\
\hline Wald $X^{2}$ (d.f.) & & $\begin{array}{c}815.61 * * * \\
(15)\end{array}$ & $\begin{array}{c}827.64 * * * \\
(16)\end{array}$ & $\begin{array}{c}834.12 * * * \\
(16)\end{array}$ & $\begin{array}{c}834.26 * * * \\
(17)\end{array}$ & $\begin{array}{c}841.52 * * * \\
(17)\end{array}$ & $\begin{array}{c}842.01 * * * \\
(18)\end{array}$ \\
\hline Pseudolikelihooc & & -3165.19 & -3152.1 & -3160.71 & -3148.85 & -3157.28 & -3157.26 \\
\hline $\begin{array}{l}\text { Hosmer- } \\
\text { Lemeshow } X^{2}(8 \\
\text { d.f.) }\end{array}$ & & 15.44 & 14.51 & $16.66^{*}$ & $19.95 *$ & 14.87 & 15.24 \\
\hline $\mathrm{R}^{2}$ McFadden & & 0.173 & 0.174 & 0.175 & 0.175 & 0.175 & 0.175 \\
\hline
\end{tabular}

Notes: Table 4 shows the probit estimates of holding a pension or retirement asset. Namely, the marginal effect of each estimate is identified. The variables LNAGE and $\mathrm{LNAGE}^{2}$ are expressed in its logarithmic form. The levels of significance are given by $\dagger$ for $10 \%$, for $5 \%$, ** for $1 \%$, and $* * *$ for $0.1 \%$. Robust standard errors are enclosed in parentheses. $d$.f. stands for the degrees of freedom.

Source: own compilation from INFE 
In this respect, some authors insist that the effect of self-control on financial behaviours can be affected by the individual's financial literacy (Farrell et al., 2016; Strömbäck et al., 2017). To test whether the effect of self-control differs depending on individuals' financial literacy, Model 5 is re-estimated by interacting the dummy variable on self-control with that on financial literacy (see Model 6). Whereas the variable concerning self-control remains statistically significant and positively related to the investment in retirement assets, the financial literacy variable does not seem to be significant. Similarly, the interaction term between selfcontrol and financial literacy fails to be statistically significant. However, in the probit models, this lack of significance does not necessarily imply that the interaction effect is zero (Norton, Wang, \& Ai, 2004), since in nonlinear models the magnitude of the interaction effect does not equal the marginal effect (Ai \& Norton, 2003).

To go further on this issue, we compute the mean marginal effect and significance level of the interaction terms using Stata's inteff command (Norton et al., 2004), that are displayed in Graph 1. The results confirm that both the individual's self-control and financial literacy positively influence the decision to invest in retirement assets. Moreover, the results seem to indicate that the level of self-control exerts its influence on the probability of holding retirement assets, especially among those individuals who display high levels of financial literacy. However, this 'incremental' effect shows a diminished impact in the sample composed of individuals with low and medium levels of financial literacy.

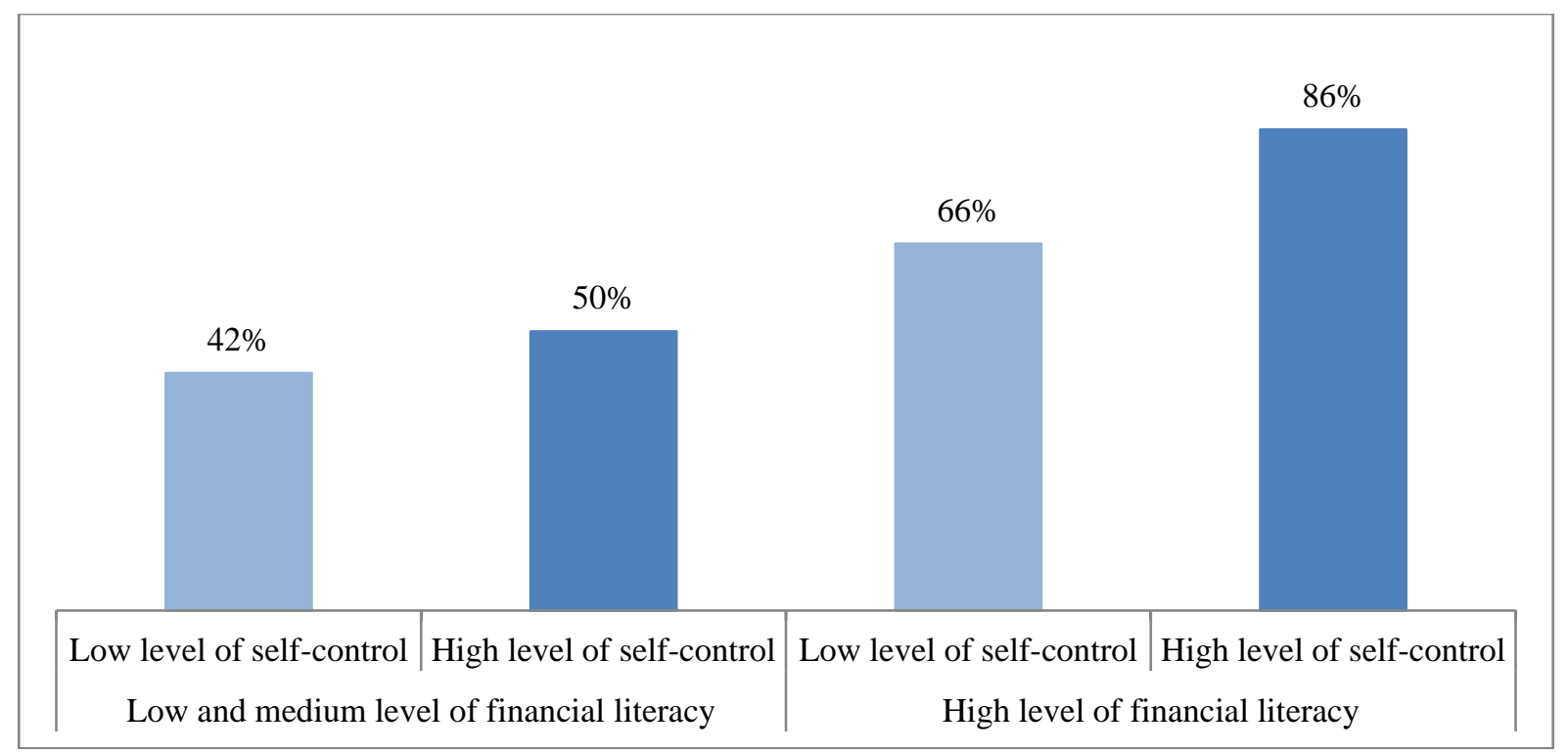

Graph 1. Marginal effects of the interaction's terms

Source: own data from INFE

Additionally, as regards the control variables, empirical evidence allows us to confirm that the decision to hold pension or retirement assets is positively related to households' income level and individuals' educational attainment and age; even though the effect of age decreases as the individual ages, thus showing an inverted U-shape. As compared to those who are employed or self-employed, people in other employment situations have lower probabilities of holding pension or retirement assets. Empirical evidence also reveals that women are less likely than men to hold retirement assets. The remaining control variables are not significant. 


\section{Conclusions}

Population ageing has long been identified as a threat to the sustainability of the Spanish public pension system; a threat that in the aftermath of the most recent financial crisis became even more explicit. In this regard, private retirement savings constitute an available option to improve this sustainably, which motivated extensive research into the driving forces of this financial decision. This research has considered different approaches, e.g., demographic, socioeconomic and so on, to understand the mechanisms behind this decision; however, little research has been conducted on the effect of personality and behavioural driving forces.

This paper is aimed at demonstrating that the ability of individuals to control their emotions and impulses related to money, i.e., the individuals' self-control, and the individuals' knowledge regarding financial concepts, i.e., financial literacy, play a role in the decision to hold retirement assets. Drawing on the behavioural life-cycle hypothesis, the results of the estimated probit models confirm that higher levels of financial self-control are positively associated with retirement savings.

Empirical evidence has also revealed that self-control acts together with other control variables such as financial literacy. In this regard, financially literate individuals who display high levels of self-control are more likely to hold voluntary pension or retirement assets, compared to financially literate individuals with low levels of self-control. In other words, it can be said that self-control leverages the probability of holding pension or retirement assets among financially literate individuals. However, among those with low levels of financial literacy, this incremental effect is much smaller.

The findings of this study have major policy and managerial implications. The first implication is the need to educate individuals about financial issues and provide them with the tools that generate the confidence to assume their own financial decisions and risks. Nevertheless, improving individuals' financial literacy is not enough. The second implication that emerges from the analysis is the relevance of improving the ability of individuals to properly manage and control their own money. This will be conditioned by the individual's level of self-control when making financial decisions. In this respect, it is necessary to supplement financial education by providing individuals with strategies to control their own impulses when making financial decisions; and here, psychology might play a role. A third implication refers to financial institutions, especially those in the fintech industry, that need to seriously consider the role played by self-control in financial behaviours. The design of apps for financial issues should ethically include filters to prevent the individual's 'first impulse', as well as tools to foster long-term saving habits.

Despite its contributions, this paper presents some potential limitations that open the way for future research. Firstly, this study is based on cross-sectional data; and therefore, to arrive at causality conclusions, future studies should be based on longitudinal data. In this regard, data was collected in 2015, and even though a more recent sample would be desirable, only one edition of the International Survey of Adult Financial Literacy is available to date. Secondly, a sample of Spanish individuals is considered; whereas future studies could replicate the study for other countries and make a comparative analysis. Finally, although we have used a more complete measure of self-control than previous studies, there is a possibility that some important aspects of the variable have been omitted. 


\section{References}

Achtziger, A., Huber, M., Kenning, P., Raab, G., \& Reisch, L. (2015). Debt out of control: The links between self-control, compulsive buying, and real debts. Journal of Economic Psychology, 49, 141-149. doi: 10.1016/j.joep.2015.04.003

Ai, C., \& Norton, E. C. (2003). Interaction terms in logit and probit models. Economics Letters, 80(1), 123-129. doi: 10.1016/s0165-1765(03)00032-6

Ameriks, J., Caplin, A., Leahy, J., \& Tyler, T. (2007). Measuring self-control problems. American Economic Review, 97(3), 966-972. doi: 10.1257/aer.97.3.966

Antonides, G., De Groot, I. M., \& Van Raaij, W. F. (2011). Mental budgeting and the management of household finance. Journal of Economic Psychology, 32(4), 546-555. doi: 10.1016/j.joep.2011.04.001

Atkinson, A., \& Messy, F. A. (2011). Assessing financial literacy in 12 countries: an OECD/INFE international pilot exercise. Journal of Pension Economics \& Finance, 10(4), 657-665. doi: 10.1017/s1474747211000539

Baumeister, R. F., Vohs, K. D., \& Tice, D. M. (1994). The strength model of self-control. Current Directions in Psychological Science, 16(6), 351-355. doi:10.1111/j.14678721.2007.00534.x

Farrell, L., Fry, T. R. L., \& Risse, L. (2016). The significance of financial self-efficacy in explaining women's personal finance behaviour. Journal of Economic Psychology, 54, 85-99. doi: 10.1016/j.joep.2015.07.001

Gathergood, J. (2012). Self-control, financial literacy and consumer over-indebtedness. Journal of Economic Psychology, 33, 590-602. doi: 10.1016/j.joep.2011.11.006

Gathergood, J., \& Weber, J. (2014). Self-control, financial literacy \& the co-holding puzzle. Journal of Economic Behavior \& Organization, 107, 455-469. doi:10.2139/ssrn.2005031

Hair, J. F., Black, W. C., Babin, B. J., Anderson, R. E., \& Tatham, R. L. (2006). Multivariate data analysis. Upper Saddle River, NJ: Pearson.

Hershey, D. A. (2004). Psychological influences on the retirement investor. CSA: Certified Senior Advisor, 22, 31-39.

Hira, T. K., Rock, W. L., \& Loibl, C. (2009). Determinants of retirement planning behaviour and differences by age. International Journal of Consumer Studies, 33(3), 293-301. doi: 10.1111/j.1470-6431.2009.00742.x

Kimball, M., \& Shumway, T. (2009). Fatalism, Locus of Control and Retirement Saving. University of Michigan.

Lim, H., Heckman, S., Montalto, C. P., \& Letkiewicz, J. (2014). Financial stress, self-efficacy, and financial help-seeking behavior of college students. Journal of Financial Counseling and Planning, 25(2), 148-160.

Lown, J. M. (2011). Development and validation of a financial self-efficacy scale. Journal of Financial Counseling and Planning, 22(2), 54-64.

Lown, J. M., Kim, J., \& Gutter, M. S. (2015). Self-efficacy and Savings among Middle and Low Income Households. Journal of Family and Economic Issues, 36, 491-502. doi:10.1007/s10834-014-9419-y

Lusardi, A. (2008). Financial literacy: an essential tool for informed consumer choice? Working Paper, Dartmouth College. doi: 10.3386/w14084

Lusardi, A., \& Mitchell, O. (2011). Financial literacy and retirement planning in the United States. Journal of Pension Economics and Finance, 10(4), 509-525. doi:10.1017/S147474721100045X 
Modigliani, F., \& Brumberg, R. (1954). Utility analysis and the consumption function: an interpretation of cross-section data. In: K. Kurihara (Ed.). Post-Keynesian Economics (pp. 388-436). New Jersey: Rutgers University Press.

Norton, E. C., Wang, H., \& Ai, C. (2004). Computing interaction effects and standard errors in logit and probit models. The Stata Journal, 4(2), 154-167. doi:10.1177/1536867x0400400206

Ricci, O., \& Caratelli, M. (2017). Financial literacy, trust and retirement planning. Journal of Pension Economics and Finance, 16(1), 43-64. doi: 10.1017/S1474747215000177

Shefrin, H. M., \& Thaler, R. H. (1988). The behavioral life-cycle hypothesis. Economic Enquiry, 66, 609-643. doi: 10.1111/j.1465-7295.1988.tb01520.x

Sotiropoulos, V., \& d'Astous, A. (2013). Attitudinal, self-efficacy, and social norms determinants of young consumers' propensity to overspend on credit cards. Journal of Consumer Policy, 36(2), 179-196. doi: 10.1007/s10603-013-9223-3

Strömbäck, C., Lind, T., Skagerlund, K., Västfjäll, D., \& Tinghög, G. (2017). Does selfcontrol predict financial behavior and financial well-being? Journal of Behavioral and Experimental Finance, 14, 30-38. doi: 10.1016/j.jbef.2017.04.002

Tangney, J. P., Baumeister, R. F., \& Boone, A. L. (2004). High self-control predicts good adjustment, less pathology, better grades, and interpersonal success. Journal of Personality, 72(2), 271-324. doi: 10.1111/j.0022-3506.2004.00263.x

Wang, L., Lu, W., \& Malhotra, N. K. (2011). Demographics, attitude, personality and credit card features correlate with credit card debt: A view from China. Journal of Economic Psychology, 32(1), 179-193. doi: 10.1016/j.joep.2010.11.006 